\title{
ANALYSIS OF DESIGN OF PURE ETHANOL ENGINES
}

\author{
Alberto Boretti \\ University of Ballarat, Ballarat, Victoria, Australia \\ Copyright $\odot 2010$ SAE International
}

\begin{abstract}
Ethanol, unlike petroleum, is a renewable resource that can be produced from agricultural feed stocks. Ethanol fuel is widely used by flex-fuel light vehicles in Brazil and as oxygenate to gasoline in the United States. Ethanol can be blended with gasoline in varying quantities up to pure ethanol (E100), and most modern gasoline engines well operate with mixtures of 10\% ethanol (E10). E100 consumption in an engine is higher than for gasoline since the energy per unit volume of ethanol is lower than for gasoline. The higher octane number of ethanol may possibly allow increased power output and better fuel economy of pure ethanol engines vs. flexifuel engines. High compression ratio ethanol only vehicles possibly will have fuel efficiency equal to or greater than current gasoline engines. The paper explores the impact some advanced technologies, namely downsizing, turbo charging, liquid charge cooling, high pressure direct injection, variable valve actuation may have on performance and emission of a pure ethanol engine. Results of simulations are described in details providing guidelines for development of new dedicated engines.
\end{abstract}

\section{INTRODUCTION}

Ethanol is an alternative fuel resulting in less greenhouse gas (GHG) emissions than gasoline [1]. The key environmental benefit of ethanol is that, unlike gasoline and diesel, its consumption does not significantly raise atmospheric levels of $\mathrm{CO} 2$. This is because the $\mathrm{CO} 2$ which is released during the burning of the fuel is counterbalanced by that which is removed from the environment by photosynthesis when growing crops and trees for ethanol production. There is considerable controversy as to whether corn-based ethanol is a net positive with respect to GHG emission. Production of ethanol fuel from sugar cane is however generally accepted to produce a reduction in GHG emission. On a life cycle basis, ethanol produced today roughly reduces $20 \%$ GHG emissions [1], and in terms of fossil energy, it delivers one third or more energy than is used to produce it accounting for the energy contained in the co-products [1]. This GHG emission reduction could increase with improved efficiency and use of renewable energy, and producing ethanol from more abundant cellulosic biomass sources rather than corn or sugar cane. If ethanol has the potential to significantly reduce global GHG emissions associated with transportation, controls are definitely needed to protect ecologically important lands, and the production efficiency and environmentally friendliness has to be incontestably improved.

Ethanol blends in use today have little impact on fuel economy or vehicle performance. Ethanol is available in various blends, most commonly E5, E10, E85, E100, where the E stands for ethanol and the number denotes the $\%$ of ethanol in the blend. Ethanol delivers less energy per liter than gasoline, but has an increased resistance to knock. Most modern gasoline vehicles may be fuelled with gasoline blended with small amounts of ethanol,

Page 1 of 13 
gasoline, E10 or any mixture of the two, with no perceptible effect on fuel economy. Flex-fuel vehicles may be fuelled with both gasoline and ethanol in any proportions. Hardware modifications are needed, including more durable valves and valve seats, and the use of ethanol-compatible materials in the fuel system. Today's flex-fuel vehicles can run on E85, gasoline or any mixture of the two, with automatic fuel adjustments of engine operation [2]. E85 has a much higher octane rating than gasoline, and turbocharged flexi-fuel engines [2] may use higher boost pressure and more advanced ignition timing than on gasoline without risk of knocking or predetonation. The compression ratio of the engine is however fixed to the minim value needed when running gasoline, and further benefits in terms of reduction of $\mathrm{CO} 2$ production and use of fossil fuels may therefore be obtained running the higher compression ratio pure ethanol engines that are the subject of the paper, where direct injection is added to turbo charging to fully exploit the advantages of ethanol's higher research octane number and higher heat of vaporization.

Pure ethanol engines are not a new idea. They have been very popular in Brazil in the 80s. Brazil has been the pioneering country in the use of ethanol as a road transport fuel, starting its experience in between the two world wars. Sugar cane has been one of the main resources of Brazil since the 1500s, and sugar cane crops are the basis for ethanol production in Brazil. In the 70s, increased oil prices convinced the Brazilian government to launch the Pro-alcohol program to help reduce the country's dependence on oil replacing gasoline with ethanol made from sugar. In the early 80s almost all cars sold in Brazil ran on ethanol. As oil prices dropped in the latest 80s, the Brazilian government suddenly decreased support for ethanol production, and production volumes stagnated despite the fact that demand remained strong. A serious supply crisis occurred in 1989, when drivers where not able to find the pure ethanol fuel required to run the not flex-fuel cars. The supply crisis and the subsequent loss of consumer's confidence in pure ethanol fuelled cars plus the oil prices affordable over again plunged the popularity of ethanol-powered cars. When oil prices returned high, ethanol in Brazil rebounded, but this time car manufacturers designed flex-fuel cars powered by any mixture of gasoline and ethanol, allowing the driver to choose whichever fuel was cheaper or more easily available. The additional benefits in terms of reduction of $\mathrm{CO} 2$ production and use of fossil fuels and a more mature, environmentally friendly and sustainable ethanol industry may renew the scope of pure ethanol engines having efficiencies much better than gasoline.

Turbo charging is one of the main advantages of Diesel engines, now being considered also for gasoline engine applications to improve both the power density and the fuel conversion efficiency. Although the main advantages of Diesel are high compression ratio and lean operation, turbo charging increases the power density which is otherwise low due to lean operation and offers efficiency benefits partially recovering the exhaust heat to compress the intake air.

Gasoline engine turbo charging technology was specifically developed for racing applications during the so called Turbo Era in Formula One from 1977 to 1989, and it is now an area of major concerns for new passenger car engines because of the benefits on vehicle economy through recovery of exhaust waste energy boosting the fuel conversion efficiency and the opportunity cycles thanks to downsizing to run higher brake mean effective pressures with the embedded reduced penalties in fuel conversion efficiency during emission. The turbo charged port fuel injected Formula One engines of the 80s were able to achieve amazing specific power and torque densities. The F1 turbo engines were 1.5 liters maximum displacement with layout $\mathrm{V}$-six. These engines where developed with the turbine waste gated to control the boost pressure, therefore leaving space for even better results in terms of power density and specific fuel consumption more completely recovering the exhaust energy to increase the boost pressure, and without the improvements of knock tendency due to the charge cooling of direct injection. 
The 1987 Honda RA167E engine [12], with restrictions on maximum fuel capacity of 195 liters and maximum boost pressure of $4 \mathrm{bar}$, was delivering a maximum power of $742 \mathrm{~kW}$ at $12000 \mathrm{rpm}$, and a maximum torque of $664 \mathrm{~N} \cdot \mathrm{m}$ at 9800 , corresponding to a brake mean effective pressure BMEP of 55.85 bar. The fuel-to-air equivalence ratio was 1.23, compression ratio 7.4:1, intake air temperature after intercooler $40^{\circ} \mathrm{C}$, spark timing maximum brake torque or knock limited. Fuel was a RON 102 mixture of toluene, normal heptane and isooctane. The 1988 Honda RA168E engine [12], with restrictions on maximum fuel capacity of 150 liters and maximum boost pressure of $2.5 \mathrm{bar}$, was delivering $504 \mathrm{~kW}$ at $12500 \mathrm{rpm}$, and maximum torque of $424 \mathrm{~N} \cdot \mathrm{m}$ at $10000 \mathrm{rpm}$, corresponding to a BMEP of 35.66 bar. The fuel-to-air equivalence ratio was 1.15, compression ratio 9.4:1, intake air temperature after intercooler $40^{\circ} \mathrm{C}$, spark timing maximum brake torque or knock limited. At maximum power, with a spark advance of $35^{\circ}$ crank angle BTDC, maximum pressure was 167 bar at $17^{\circ}$ crank angle ATDC, while IMEP was 38 bar. Operating with intake air temperature of $70^{\circ} \mathrm{C}$ and a fuel-to-air equivalence ratio of 1.02, the minimum brake specific fuel consumption BSFC was $272 \mathrm{~g} / \mathrm{kWh}$, while the maximum power was $456 \mathrm{~kW}$ at $12500 \mathrm{rpm}$.

The paper explores the advantages direct injection and high turbo charging may give to pure ethanol engines fully exploiting the reduced knock tendency and the increased heat of vaporization of ethanol when compared to gasoline. The high evaporation enthalpy of ethanol requires detailed examinations regarding the cold start behavior [16-23]. Various injection strategies should be adopted to avoid the fuel film on the piston top and ensure that the first injected mass of fuel could also be ignited [16]. The larger amounts of fuel to be injected with ethanol may also increase the oil dilution. Both these aspects are not considered in the paper. Peak cylinder pressures and turbine inlet temperatures of the following application are compatible with values used in racing applications of the 70s. Peak cylinder pressures are higher than those of today's production gasoline engines, but close to those of today's production Diesel engines. Cost related thermal and structural limitations to boost are not considered in the present paper.

\section{DIRECT INJECTION TURBO CHARGED E100 ENGINE}

Ethanol has many advantages and disadvantages when compared to gasoline as a fuel [3 to 9]. Gasoline blends differ, and properties of gasoline vary with type. Nevertheless, it is possible to define reference values for gasoline as well as of ethanol to compare. When reference is made to gasoline, ethanol has a smaller Lower Heating Value (LHV), about 26.8 MJ/Kg vs. $43.2 \mathrm{MJ} / \mathrm{Kg}$. However, the stoichiometric air/fuel ratio for ethanol is also smaller than the one for gasoline, 9.0078 vs. 14.6, or the fuel-to-air ratio is larger, $0.111 \mathrm{vs.} 0.068$, and therefore, the amount of energy per kg of stoichiometric mixture is similar for ethanol and gasoline, respectively $2.68 \mathrm{MJ} / \mathrm{Kg}$ vs. $2.77 \mathrm{MJ} / \mathrm{Kg}$. Ethanol has a much larger Research Octane Number (RON), roughly 129 vs. 95. These permits higher compression ratios, higher boost in turbocharged engines, and better knock limited spark advances. Ethanol also has a larger heat of vaporization, respectively $841 \mathrm{~kJ} / \mathrm{kg} v s .360 \mathrm{~kJ} / \mathrm{kg}$. The amount of energy available per $\mathrm{kg}$ of stoichiometric mixture to cool the charge is therefore $84.1 \mathrm{~kJ} / \mathrm{kg} \mathrm{vs.23} \mathrm{kJ/kg}$. This permits higher densities in the intake that may increase volumetric efficiency especially in naturally aspirated engines with PFI engines, or better cooling of the in-cylinder charge in both naturally aspirated and turbo charged DI engines. This latter feature further reduces the knock sensitivity. Densities of gasoline and ethanol are similar, respectively $750 \mathrm{~kg} / \mathrm{m} 3$ vs. $786 \mathrm{~kg} / \mathrm{m} 3$. However, fuel injection systems must handle larger quantities of fuel because of the lower energy content. Therefore, DI fuel injectors developed for gasoline applications should probably be revised for higher flow areas or increased injection pressures to efficiently operate with ethanol.

If direct fuel injection and turbo charging are two of the most effective directions in improving the efficiency of gasoline engines, there is no doubt pure ethanol engines should follow these trends. The evaporative cooling from direct ethanol injection, coupled with the high octane rating of ethanol, has been already proved to be 
highly effective in inhibiting knock [5]. Direct injection and turbo charging may therefore optimize pure ethanol-fuelled engines to a level of performance that exceeds gasoline engine efficiency taking full advantage of ethanol's higher research octane number and higher heat of vaporization. Therefore, simulations have been performed using the WAVE code [10] for an in-line four spark ignition engine. Combustion is simulated with a predictive SI turbulent combustion model [10 and 13], while knock is simply computed with an empirical induction-time correlation model [10 and 14].

The simple knock model is a well known induction time correlation [14]. The induction time in seconds is calculated at every time step using the following equation:

$$
\tau=0.01869 / A_{p} *\left(\frac{O N}{100}\right)^{3.4107} * P^{-1.7} \exp \left(\frac{3800 / A_{T}}{T}\right)
$$

where Ap is a pre-exponential multiplier, ON the fuel octane number, $\mathrm{P}$ the cylinder pressure $[\mathrm{kg} / \mathrm{cm} 2], \mathrm{AT}$ the activation temperature multiplier and $\mathrm{T}$ the unburned gas temperature $[\mathrm{K}]$. This induction time continually decreases as combustion progresses and the unburned zone temperature rises. The end-gas auto-ignites (knocks) if the induction time is less than the flame arrival time. The model assumes that auto-ignition occurs when:

$\int_{t 0}^{t i} \frac{d \tau}{\tau}=1$

where t0 is the start of end-gas compression, ti the time of auto-ignition and $\mathrm{t}$ is the induction time. WAVE [10] has the option to eventually introduce a post-knock burn acceleration, when knock occurs, a spontaneous mass burning rate due to knock is determined and fed back to the cylinder, leading to rapid rise in cylinder pressure and temperature. The in-cylinder heat transfer coefficient is also increased during knock. Combustion is then governed by the post-knock burn time scale as shown below:

$\tau_{\text {postinock }}=f_{\varepsilon}\left[\frac{0.8573}{B_{0}(1+A / F)} \exp \left(\frac{T_{a}}{T_{f}}\right)\right]$

Where ft is the post-knock burn scale multiplier, B0 a frequency factor, A/F the air-to-fuel ratio of the unburned end gas, Ta the activation temperature, Tf the adiabatic flame temperature. The fuel burn rate in the post-knock period is assumed to be constant and is calculated as:

$m_{\text {dot,flel }}=\frac{m_{\text {flapor }}+m_{\text {fliquid }}}{\tau_{\text {postinock }}}$

While air is burned proportionally at a rate given by:

$m_{\text {dot, air }}=m_{\text {dot, flel }} *(A / F)$

where mfvapor is the unburned fuel vapor mass at the time of knock and mfliquid the nburned fuel liquid mass at the time of knock.

Page 4 of 13 
The engine is turbo charged with a fixed geometry turbine, and it has charge cooling, waste gate and exhaust gas recirculation. The main engine parameters are presented in Table 1. Fuel is directly injected within the cylinder and the engine is running stoichiometric to lower the emission of pollutants below Euro 4 standards with a three way catalytic converter (TWC). The engine has four valves per cylinder. Piston is modified to run ethanol with an increased compression ratio 13:1 and better deal with the different fuel spray.

The injection pressure from the fast actuating, multiple event high pressure injector is increased from 200 to 300 bar with ethanol. With E100, the DI injector maximum flow rate shall be increased since E100 only contains $66 \%$ of gasoline energy in volume. The problem was solved using a higher pressure GDI injector specifically developed for much larger engines (the displaced volume for a single cylinder of this engine is only 0.4 liters). Injection is always performed after Intake Valve Closure (IVC). This has the advantage of injecting into hotter gas which helps to insure complete vaporization of the ethanol and prevents or minimizes wall wetting. The engine has the option to be controlled by throttle and by reducing the intake valve lift.

Table 1 - Engine parameters.

\begin{tabular}{|l|l|}
\hline Bore B [mm] & 80 \\
\hline Stroke S [mm] & 80 \\
\hline Bore to Stroke ratio B/S & 1 \\
\hline Connecting rod length [mm] & 135 \\
\hline Compression ratio CR (gasoline) & $9: 1$ \\
\hline Compression ratio CR (ethanol) & $13: 1$ \\
\hline Intake valve reference diameter Di [mm] & 27 \\
\hline Exhaust valve reference diameter De [mm] & 24 \\
\hline Intake valve maximum lift hi [mm] & 8.5 \\
\hline Exhaust valve maximum lift he [mm] & 8.5 \\
\hline Intake valve opening IVO [ ${ }^{\circ}$ crank angle] & $350^{\circ}\left(10^{\circ}\right.$ BTDC) \\
\hline Intake valve closure IVC ${ }^{\circ}$ crank angle] & $580^{\circ}\left(40^{\circ}\right.$ ABDC) \\
\hline Exhaust valve opening EVO [ ${ }^{\circ}$ crank angle] & $140^{\circ}\left(40^{\circ}\right.$ BBDC) \\
\hline Exhaust valve closure EVO ${ }^{\circ}$ crank angle] $^{\circ}$ & $370^{\circ}\left(10^{\circ}\right.$ ATDC $)$ \\
\hline
\end{tabular}

Simulations have been performed with indolene C7.3H13.9 and ethanol C2H6O1 as liquid fuels. Figures 1 to 4 present computational results obtained for normalized knock intensity and brake power, torque and efficiency. These points have been computed with wide open throttle (WOT) and maximum brake torque or knock limited spark advance. Normalized knock intensity results show that despite the much higher compression ratio, the ethanol engine is less sensitive to knock than the gasoline engine, with knock intensities less than half in the point of maximum boost from the turbo charger. The lower knock intensity is a result of the lower in-cylinder temperatures following vaporization of the ethanol fuel as well as the higher RON of ethanol. Power and torque results show the E100 engine delivers much better performance. Improvements vary from 20 to $28 \%$ over the range of engine speed. Maximum torque and power outputs are increased 20\% and 23\% respectively. In terms of fuel conversion efficiency, it increases with E100 17 to 23\%, or 5.70 to 6.25 points over the range of engine speeds.

These results are quite interesting, because the direct injection, turbo charged engine specifically designed for running ethanol, basically with few hardware modifications from a gasoline engine, may have much better fuel conversion efficiencies and power densities, while today's port fuel injected naturally aspirated flex-fuel engines still have a significant penalty in efficiency running E85 when reference is made to the base gasoline engine.

Page 5 of 13 


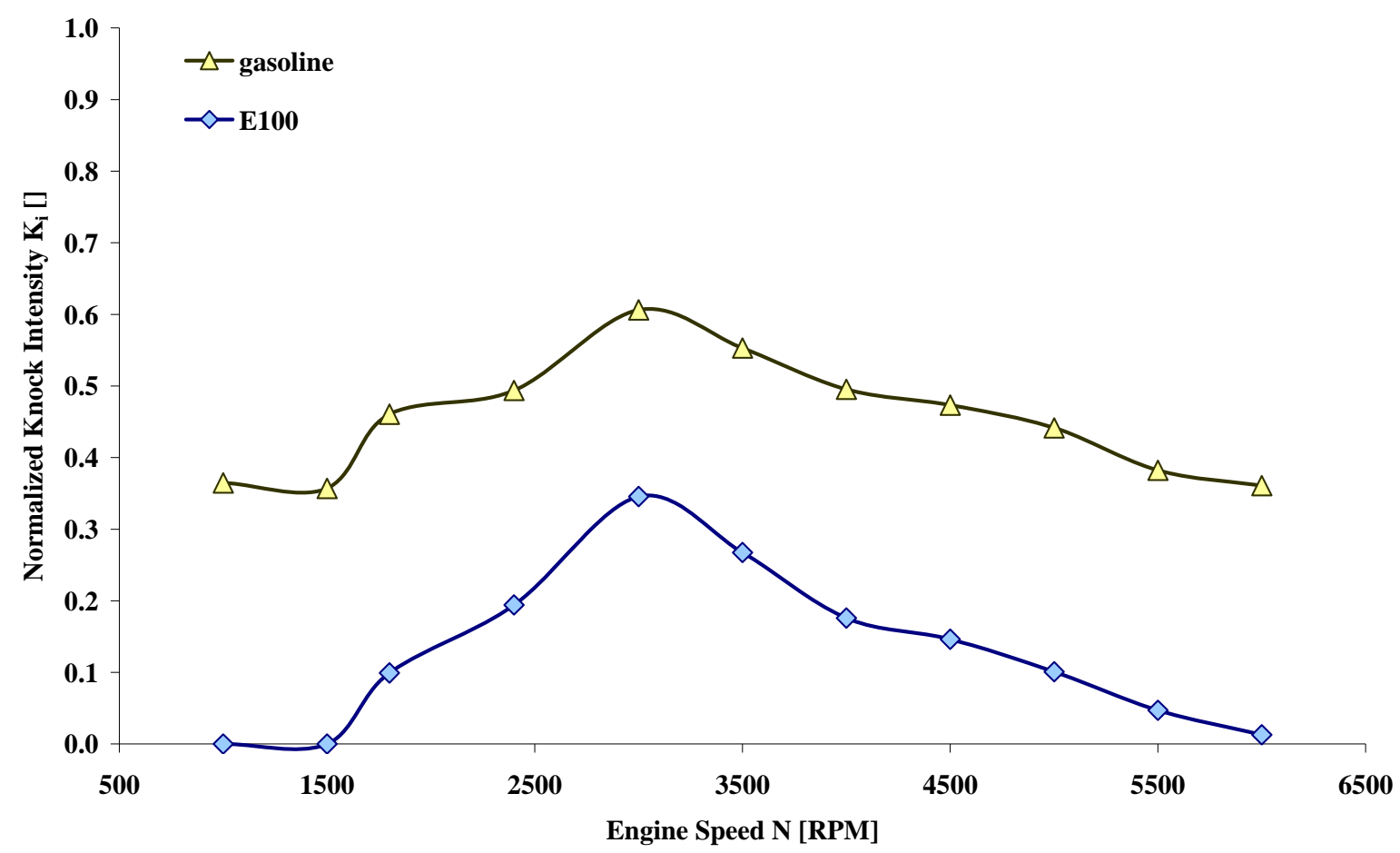

Figure 1 - Computed normalized knock intensity for gasoline and E100 engines.

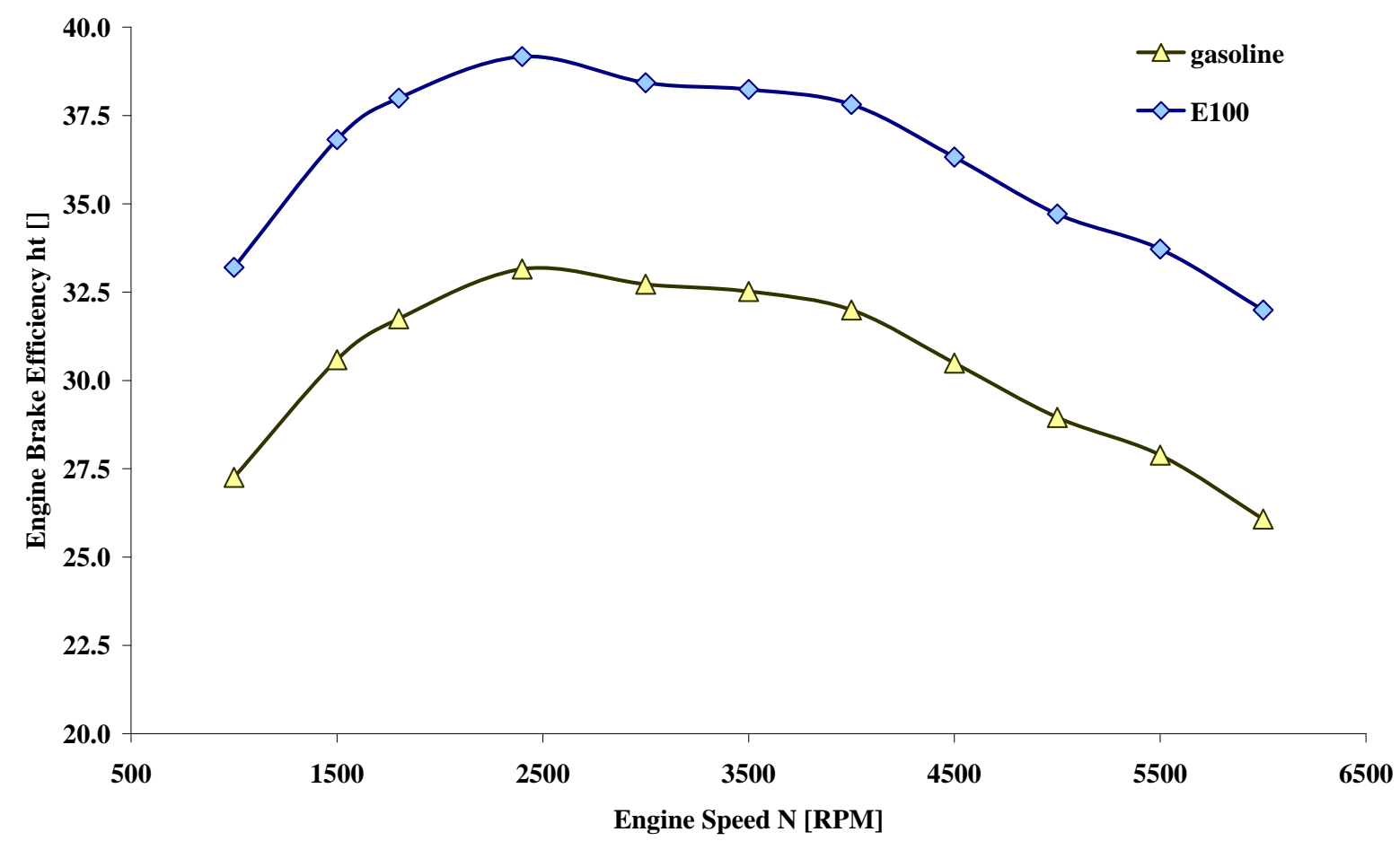

Figure 2 - Computed engine brake efficiency for gasoline and E100 engines.

Page 6 of 13 


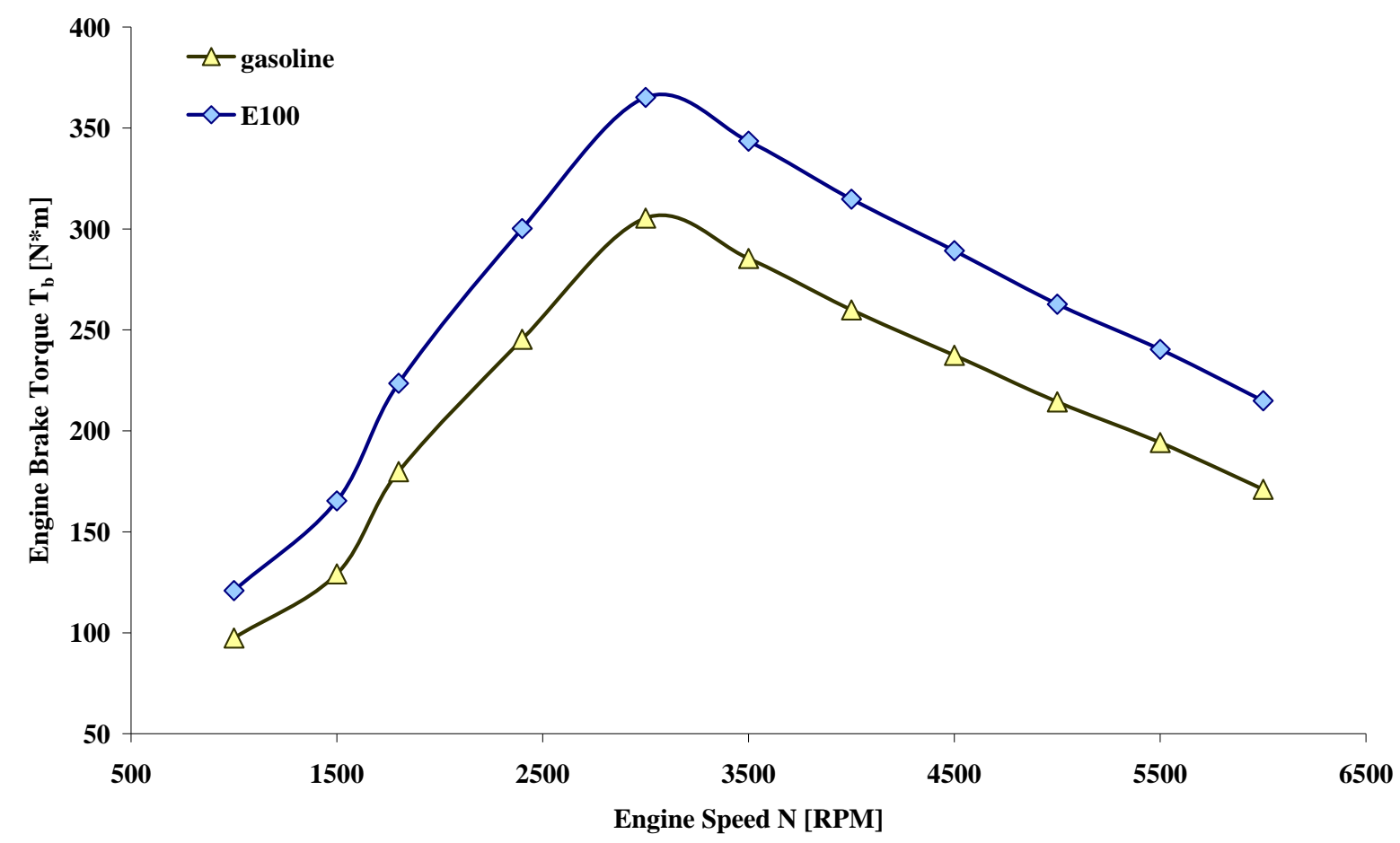

Figure 3 - Computed engine brake torque for gasoline and E100 engines.

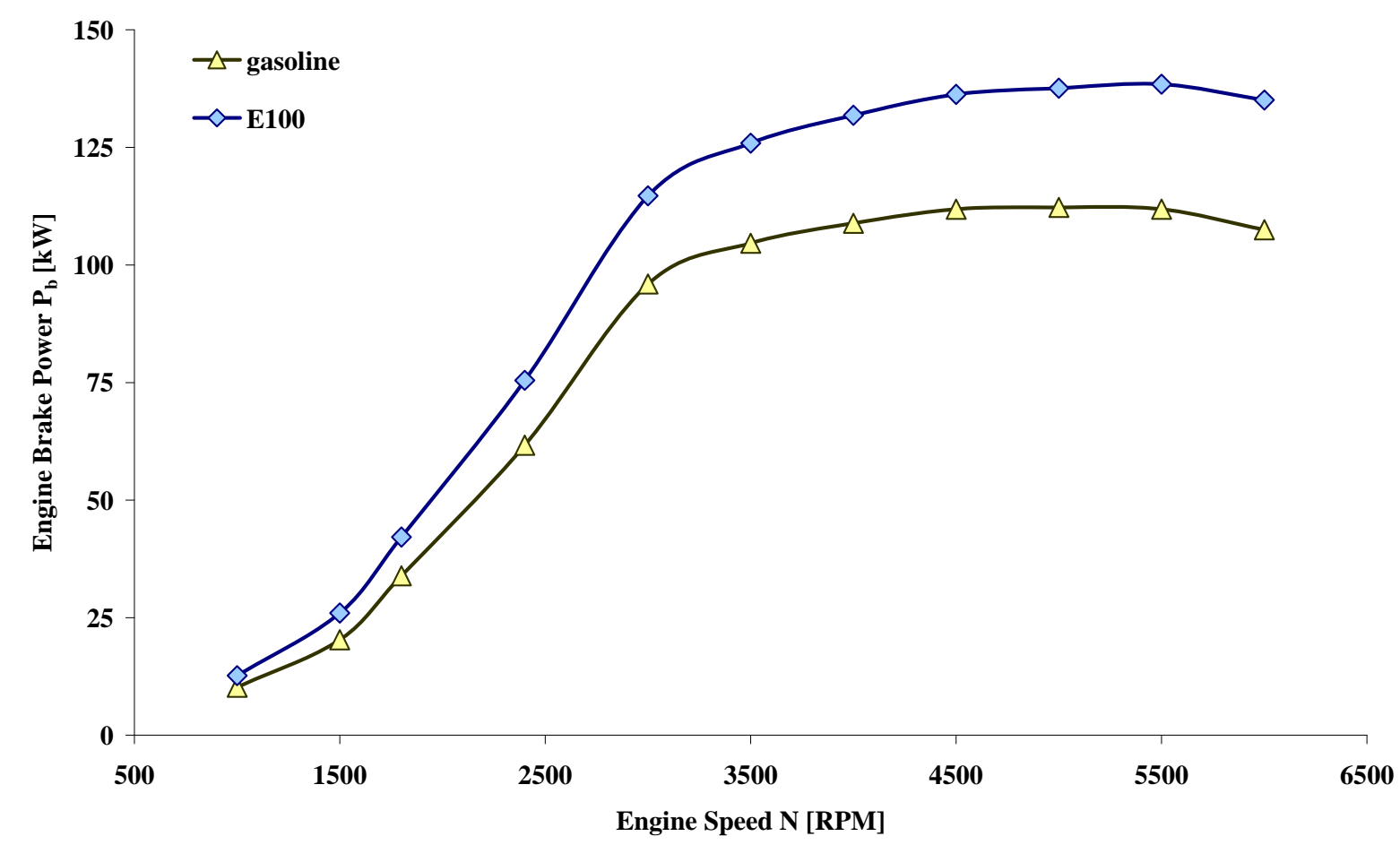

Figure 4 - Computed engine brake power for gasoline and E100 engines.

Page 7 of 13 
Further benefits in terms of fuel economy may derive from the further downsizing of the E100 engine having higher boost pressures and compression ratios. A reduction in displacement implies the engine will be used over a cycle with a proportional increase in BMEP, with the embedded benefits in terms of efficiency running higher BMEP especially significant in throttle-controlled stoichiometric engines.

Downsizing and turbo charging and direct injection may be combined with electronic valve control [11] to better deal with the challenges of fuel economy enhancement. The main issue of the spark ignition engine is the pumping losses at part load due to the traditional throttle-based load control. The throttle-less spark ignition engine control systems through variable valve actuation exhibits almost the same advantages of the traditional load control by quantity of fuel injected of Diesel engines. The use of a stoichiometric air-to-fuel mixture would permits to meet emissions standards without the negative impacts on the after treatment technology that the lean stratified operation would introduce. The electro-hydraulic variable valve actuation technology may be applied to both intake and exhaust valves to fully modify the lift profiles as needed by the engine operation. In addition to valve timing strategies as early intake valve closure or late intake valve opening, valve lift strategies are also possible with variable valve actuation. Valve lift strategies may be used to control the air quantity and the tumble charge motion in the cylinder.

Only valve lift variations are considered here to control the load. However, the variable valve actuation technology offers the potential to improve other critical areas of spark ignition engines, including better charging efficiency over the range of engine speeds and loads, improved dynamic response, better combustion evolution, improved operation during catalyst light-off time. The electro-hydraulic variable valve actuation technology is used here just to change the maximum lift to reduce the load. Better performances may be achieved fully exploiting all the benefits of the technology.

Figures 5 and 6 show the computed engine brake efficiency and mean effective pressure for the E100 engine changing the maximum intake valve lift. Controlling the load by variable valve actuation is effective in producing high efficiencies from $25 \%$ of full load.

First European test cycle with extra urban driving cycle (NEDC) simulations have then been finally performed for a large passenger car sedan with the Lotus Vehicle Simulation software [15]. The main vehicle parameters are summarized in Table 2.

Table 2 - Vehicle parameters.

\begin{tabular}{|l|l|}
\hline Mass M [kg] & 1810 \\
\hline Frontal area A [m2] & 2.250 \\
\hline Drag coefficient CD & 0.298 \\
\hline Rolling tyre radius R [m] & 0.3160 \\
\hline Transmission & 5 -speed automatic \\
\hline Transmission ratios & $3.22 / 2.29 / 1.55 / 1.00 / 0.75$ \\
\hline Final drive ratio & 2.730 \\
\hline
\end{tabular}

The 4 liter, in-line six cylinder, throttle body controlled, naturally aspirated gasoline engine with max. power $190 \mathrm{~kW}$ and maximum torque $380 \mathrm{~N} \cdot \mathrm{m}$ is replaced by the high tech, 1.6 liter, in-line four, valve lift controlled, turbo charged E100 engine described above, having $140 \mathrm{~kW}$ maximum power and $365 \mathrm{~N} \cdot \mathrm{m}$ maximum torque. Vehicle, tyre, driveline and gearbox data are kept constant. 


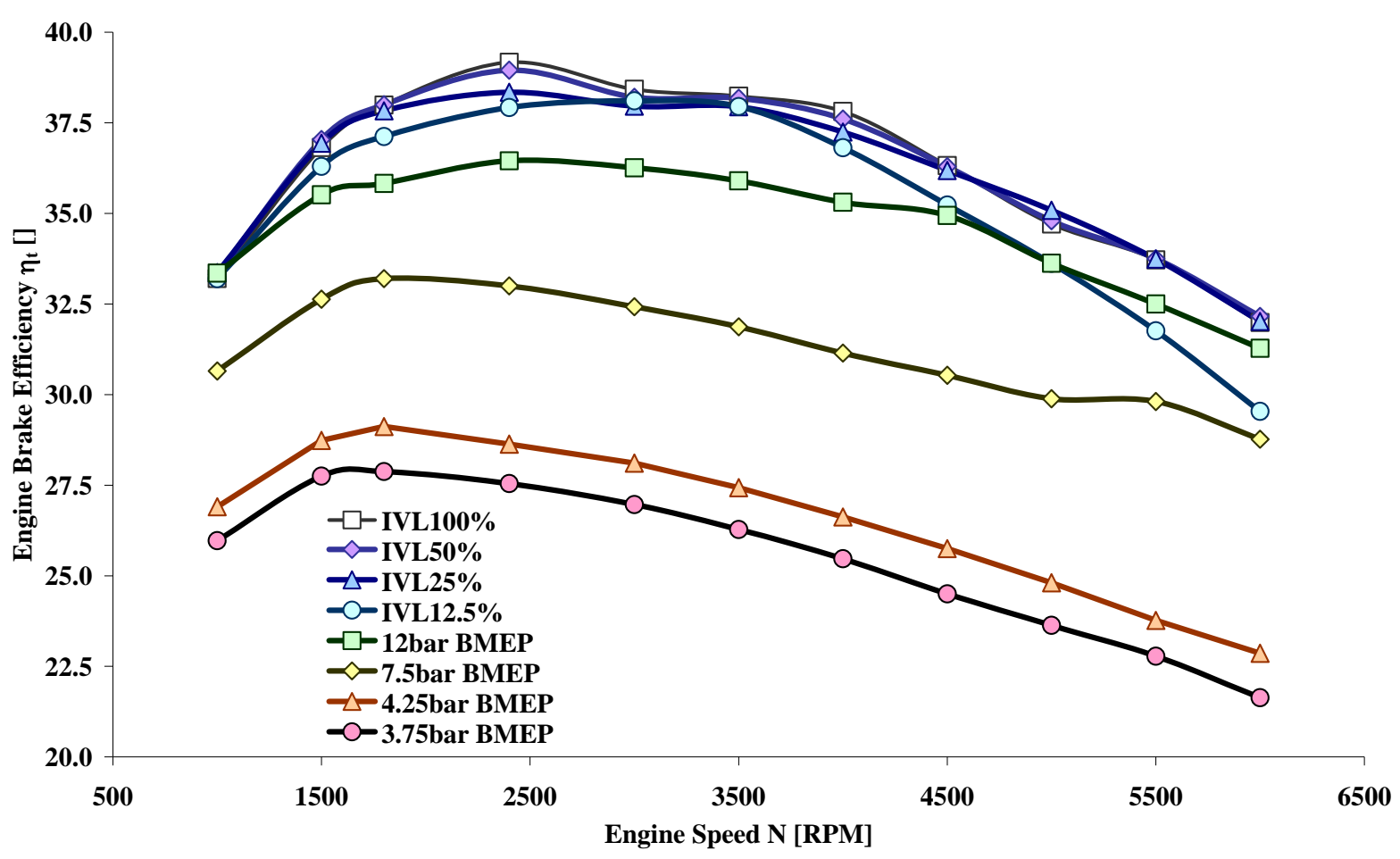

Figure 5 - Computed engine brake efficiency for the E100 engine changing the maximum intake valve lift.

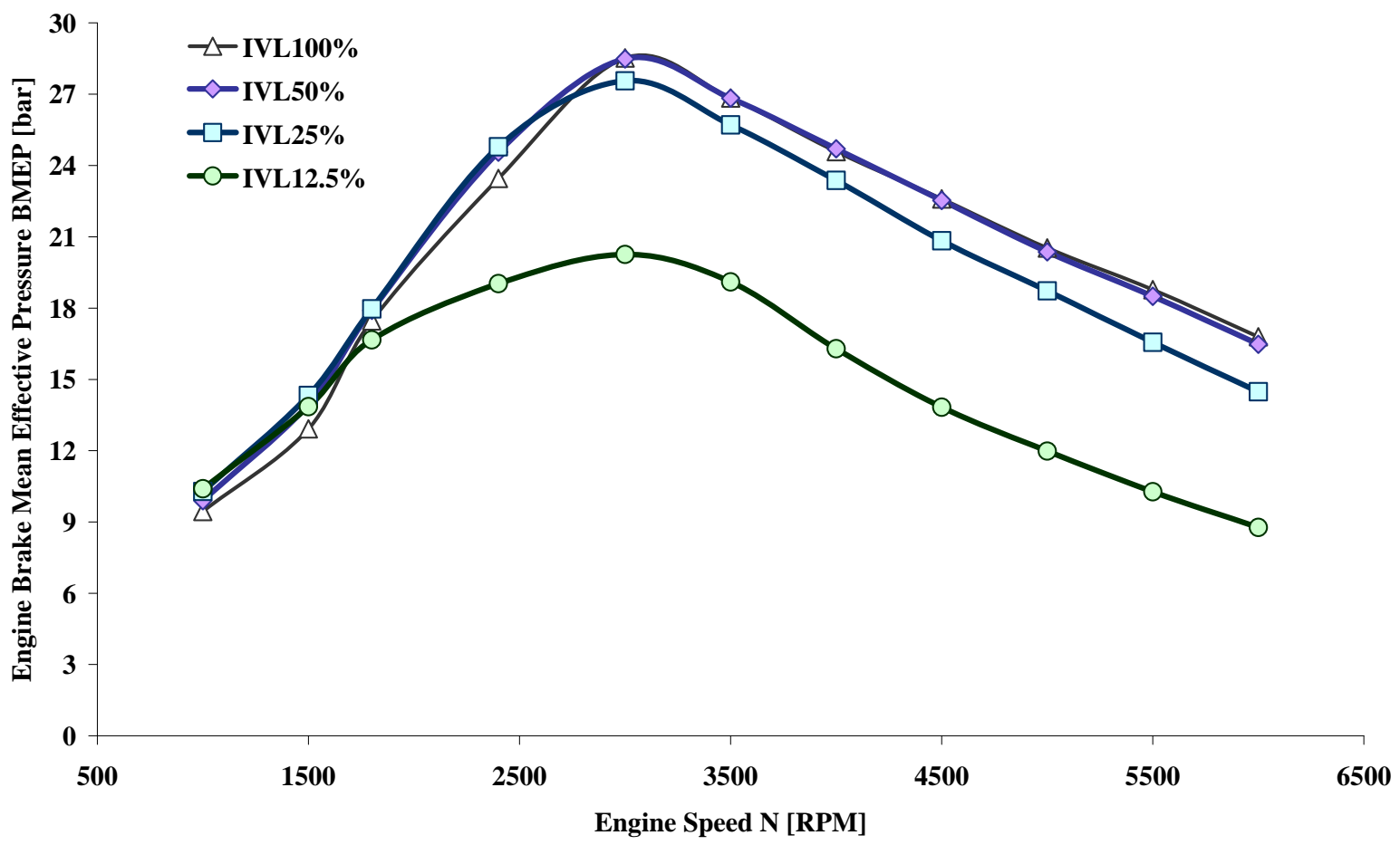

Figure 6 - Computed engine brake mean effective pressure for the E100 engine changing the maximum intake valve lift.

Page 9 of 13 


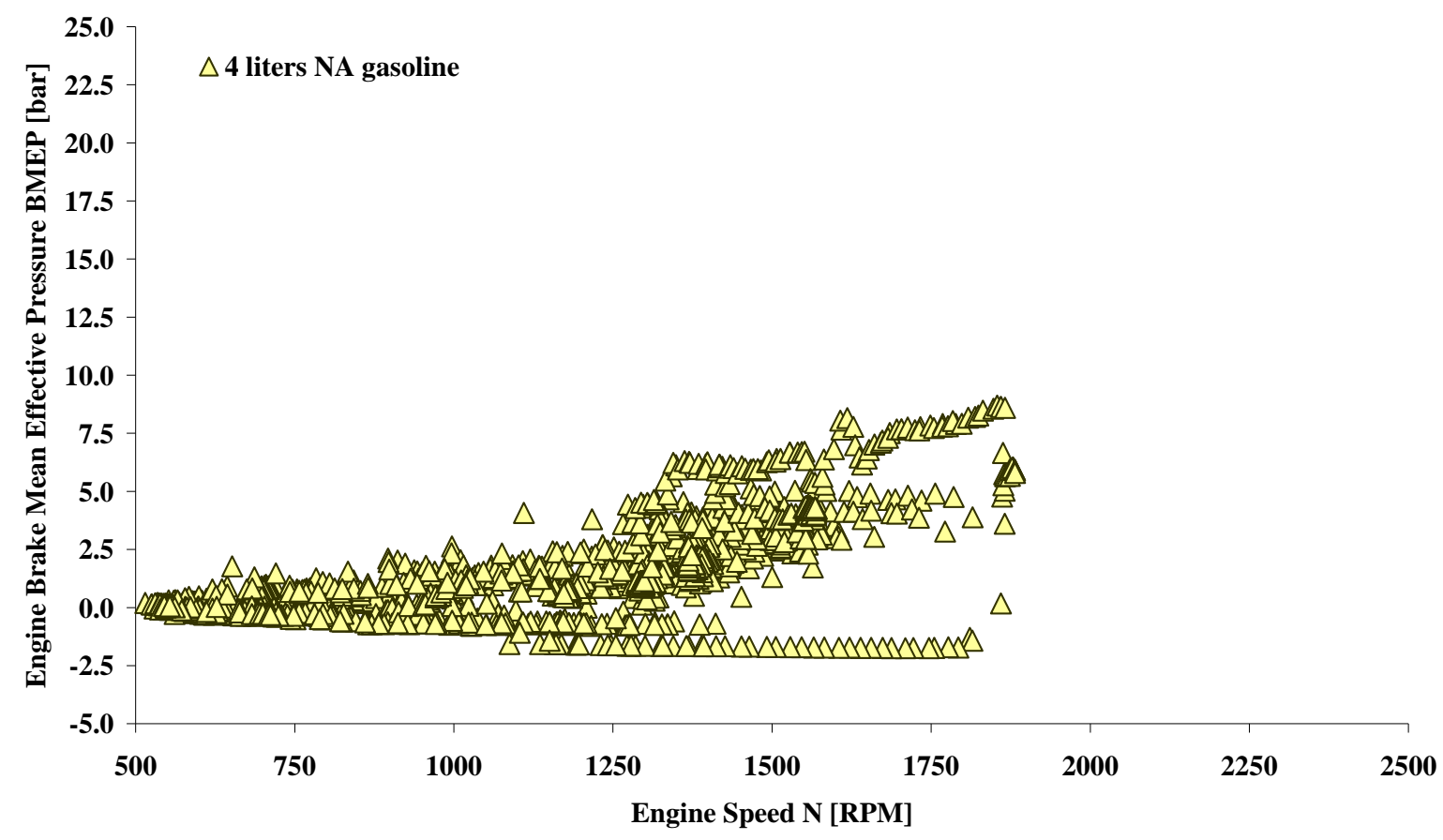

Figure 7 - Computed engine brake mean effective pressure during the NEDC for the naturally aspirated 4 liters gasoline engine.

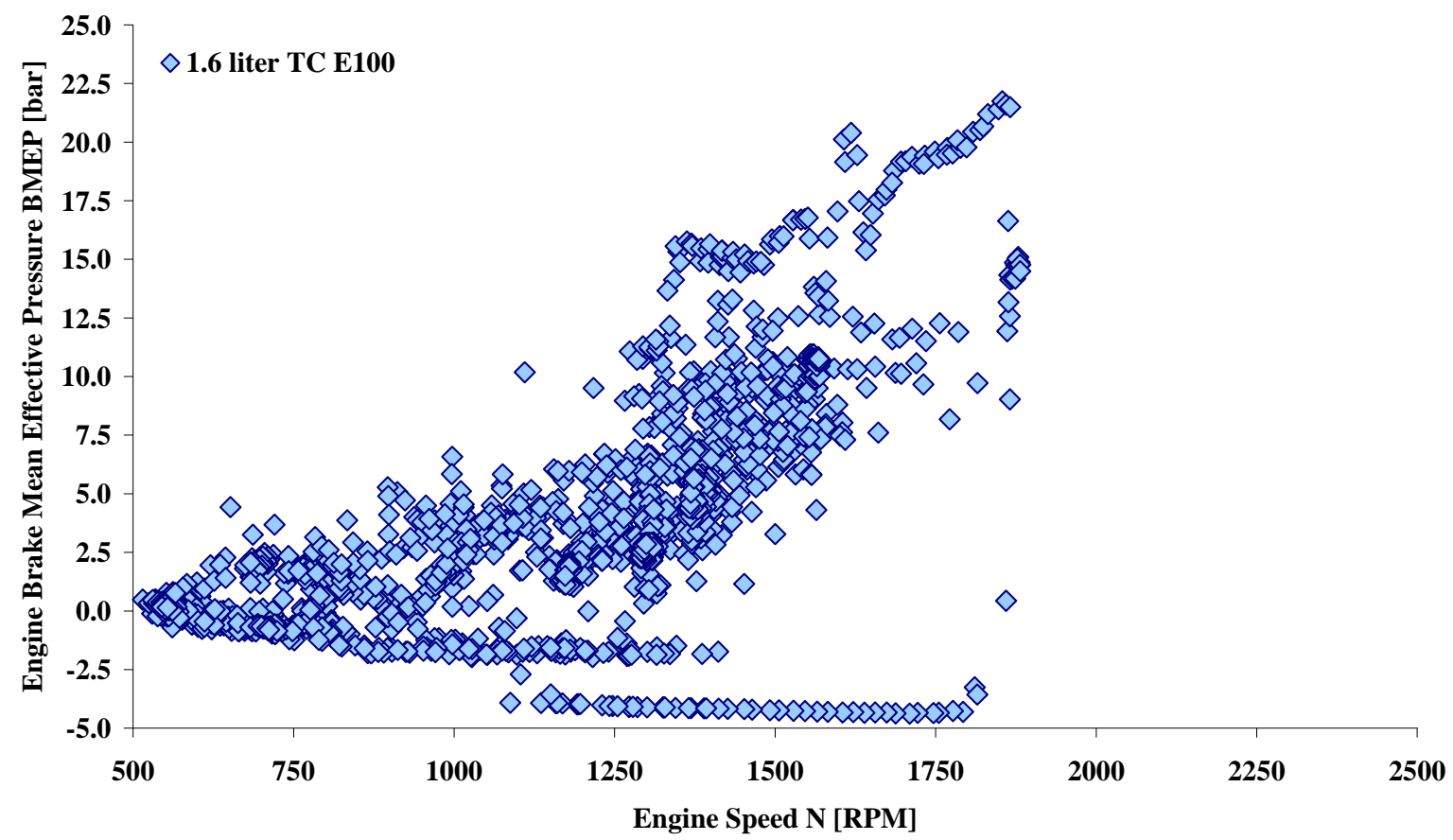

Figure 8 - Computed engine brake mean effective pressure during the NEDC for the turbocharged 1.6 liters E100 engine.

Page 10 of 13 
Figures 7 and 8 present the operating BMEP points vs. engine speed for the two engines. The displacement effect shifts up by a factor of 4/1.6 the operating BMEP. The naturally aspirated gasoline engine works the most of the time at 1.5 bar BMEP and 1500 rpm, while the turbocharged E100 engine works the most of the time at 3.75 bar BMEP and 1500 rpm.

The gasoline engine uses $936 \mathrm{~g}$ of a fuel having $\mathrm{LHV}=43.2 \mathrm{MJ} / \mathrm{Kg}$ and density $750 \mathrm{~kg} / \mathrm{m} 3$ to cover over the $1180 \mathrm{~s}$ total cycle time the $11.028 \mathrm{~km}$ distance travelled of the NEDC, for a fuel consumption of 11.3 liters per $100 \mathrm{~km}$. Even if the transmission is not optimized for the new engine, and no weight reduction is considered replacing the large naturally aspirated gasoline engine with the smaller turbo charged E100 engine, this latter engine only uses $897 \mathrm{~g}$ of a fuel having LHV=26.8 MJ/Kg and density $786 \mathrm{~kg} / \mathrm{m3}$, for a fuel consumption of 10.365 liters per $100 \mathrm{~km}$. In terms of fuel energy, the small high tech E100 engine therefore uses $40 \%$ less fuel energy than one large naturally aspirated low tech gasoline engine, permitting an even better driving range with one full fuel tank despite of the much lower energy content of E100. This is due to the higher BMEP permitted by downsizing (2.5 times larger operating BMEP following the displacement ratio), the larger top brake efficiency permitted by high compression ratio, the cooling due to direct injection cooling, the high boost from turbo charging partially recovering the exhaust waste heat, the spark advances closer to maximum brake torque, and the larger part load efficiencies due to the factors above plus the load control throttle-less by changing the lift of the intake valves.

\section{CONCLUSIONS}

Direct fuel injection and turbo charging are the key features pure ethanol engines should have to take full advantage of ethanol's higher research octane number and higher heat of vaporization. Direct injection permits to cool down the charge and improve the knock tendency. Turbo charging recover part of the exhaust energy. Direct injection and turbo charging permits higher compression ratio, higher boost pressure and spark advances less knock limited and closer to maximum brake torque for improved fuel conversion efficiency and increased power density.

The increased fuel conversion efficiency and the increased power density considerably improve fuel economy. The increased fuel conversion efficiency reduces the amount of fuel requested for a certain BMEP, the increased power density, through downsizing, permits operation at higher BMEP during the driving cycles having better efficiencies.

The proposed direct injection, turbo charged engine differs in the direct injector operating pressure and the piston shape and compression ratio to efficiently run with E100 and gasoline. The E100 has an increased injection pressure (300 bar vs. $200 \mathrm{bar}$ ) and an increased compression ratio (13:1 vs. 9:1). Improvements in power and torque vary from 20 to $28 \%$ over the range of engine speed, while the fuel conversion efficiency increases 17 to $23 \%$, or 5.70 to 6.25 points, up to values about $40 \%$.

Despite of the higher compression ratio, the closer to maximum brake torque spark advances and the reduced opening of the waste gate controlling the turbine, the E100 still have much better resistance to knock than the gasoline engine, thus leaving space for further improvements.

Variable valve actuation has been considered only for throttle-less load control. Changes of intake valve lift are effective in reducing the penalty in efficiency dropping the load. Brake efficiencies larger than those of today's naturally aspirated gasoline engines are obtained from $25 \%$ of full load over the full range of engine speed.

Page 11 of 13 
When compared to a low tech 4 liters, throttle controlled, naturally aspirated gasoline engine to power a large passenger car sedan, the small high tech turbo charged E100 engine with variable valve actuation use $43 \%$ less fuel energy over the NEDC.

Further advances may be obtained through turbo compounding, not only for the more efficient two stage compression, but also for the option to produce in the turbines additional mechanical work to the crank shaft, and use of higher efficiencies compressor and turbines. Complete variable actuation of intake and exhaust valves and advanced exhaust gas recirculation may also further help improving performance at part loads. This activity is currently in progress.

Better efficiencies both top and part load can possibly be achieved with lean burn technologies. However, considering lean burn emissions control technologies are much less developed than stoichiometric three way catalytic converter technologies for emissions control, meeting emission standards would be much more difficult. Furthermore, lean burn would reduce the power density, with the resulting issues running lower BMEP during a cycle.

\section{REFERENCES}

1. http://www1.eere.energy.gov/biomass/ (retrieved January 13, 2010).

2. http://www.saabbiopower.co.uk/ (retrieved January 13, 2010).

3. D. Bradley, "Combustion and the design of future engine fuels”, Proc. IMechE Vol. 223 Part C: J. Mechanical Engineering Science JMES1519. DOI: 10.1243/ 09544062JMES1519.

4. H. Takashi and T. Kimitoshi, "Laminar flame speeds of ethanol, n-heptane, isooctane air mixtures", Student Papers from FISITA 2006 world conference. FISITA F2006SC40. www.fisita.com/education/congress/sc06papers/f2006sc40.pdf (retrieved January 8, 2010).

5. L. Bromberg, D.R. Cohn, J.B. Heywood, "Calculations of knock suppression in highly turbocharged gasoline/ethanol engines using direct ethanol injection", MIT Laboratory for Energy and the Environment Report LFEE 2006-001. www.ethanolboost.com/LFEE-2006-01.pdf (retrieved January 14, 2010).

6. Brusstar, M., and Bakenhus, M., "Economical, high-efficiency engine technologies for alcohol fuels". http://www.epa.gov/otaq/presentations/epa-fev-isaf-no55.pdf (retrieved January 15, 2010).

7. West, B., "Enhanced Ethanol Engine And Vehicle Efficiency (Agreement 13425)", paper presented to the Energy 2008 Office of Vehicle Technologies Annual Merit Review Bethesda, Maryland, February 2008. http://www1.eere.energy.gov/vehiclesandfuels/pdfs/merit_review_2008/fuels/merit08_west.pdf

8. Brewster, S., " Initial Development of a Turbo-charged Direct Injection E100 Combustion System", SAE P. 2007-01-3625. http://www.orbeng.com/orbital/tp/pdf/2007-01-3625.pdf (retrieved January 15, 2010).

9. Brewster, S., et al., The Effect of E100 Water Content on High Load Performance of a Spray Guide Direct Injection Boosted Engine", SAE P. 2007-01-2648. http://www.orbeng.com/orbital/tp/pdf/2007-01-2648.pdf (retrieved January 15, 2010).

10. http://www.ricardo.com/en-gb/Software/Productoffering--description/WAVE1/ (retrieved January 8, 2010).

11. http://www.ae-plus.com/Technology\%20News/tn-INA-Uniair-june\%202006.htm (retrieved January 18, 2010).

12. Goto, O., et al., "Honda Formula One Turbo-charged V6 1.5L Engine", SAE P. 890877.

13. Morel, T., et al., "Model for Heat Transfer and Combustion in Spark Ignited Engines and Its Comparison with Experiments", SAE P. 880198.

14. Douaud, A. M. and P. Eyzat. "Four-Octane-Number Method for Predicting the Anti-Knock Behavior of Fuels and Engines", SAE P. 780080.

Page 12 of 13 
15. http://www.lesoft.co.uk/index1.html (retrieved January 20, 2010).

16. "Cold Start on the Transparent Engine: Ethanol Direct Injection in Turbo-Charged Spark-Ignited Engines", in AVL Combustion Measurement Newsletter Edition 2008: Combustion Analysis in Racing. http://www.avl.com/ (retrieved February 17, 2010).

17. Hakan Sandquist, Maria Karlsson, Ingemar Denbratt, "Influence of Ethanol Content in Gasoline on Speciated Emissions From a Direct-Injection Stratified Charge SI Engine", SAE P. 2001-01-1206.

18. Wei Zeng, Min Xu, Ming Zhang, Yuyin Zhang, David Cleary , "Characterization of Methanol and Ethanol Sprays from Different DI Injectors by Using Mie-Scattering and Laser Induced Fluorescence at Potential Engine Cold-Start Conditions", SAE P. 2010-01-0602 .

19. Stina Hemdal, Jonas Warnberg, Ingemar Denbratt, Petter Dahlander , "Stratified Cold Start Sprays of Gasoline-Ethanol Blends", SAE P. 2009-01-1496.

20. Atsushi Matsumoto, Yi Zheng, Xing-Bin Xie, Ming-Chia Lai, Wayne R. Moore, Matthew Foster, Keith Confer, Eunjoo Hopkins, David Yen, "Spray Characterization of Ethanol Gasoline Blends and Comparison to a CFD Model for a Gasoline Direct Injector", SAE P. 2010-01-0601.

21. Stephan Liebsch, Oliver Dingel, Jochen Maass, Michael Guenther , Matthias Kratzsch , Steffen Zwahr, "Model Based E85 Cold Start Optimization for DISI Engines", SAE P. 2009-01-1909.

22. Craig D. Marriott, Matthew Wiles, J. Michael Gwidt, Scott E. Parrish, "Development of a Naturally Aspirated Spark Ignition Direct Injected Flex-Fuel Engine", SAE P. 2008-01-0319.

23. Paul E. Kapus, Alois Fuerhapter, H. Fuchs, Guenter K. Fraidl, "Ethanol Direct Injection on Turbocharged SI Engines - Potential and Challenges", SAE P. 2007-01-1408.

\section{CONTACT INFORMATION}

Alberto Boretti, School of Science and Engineering, University of Ballarat, PO Box 663, Ballarat, Victoria 3353, Australia, email: aboretti@staff.ballarat.edu.au. 